\title{
Analisis Faktor-faktor Munculnya Word of Mouth Mempengaruhi Keputusan Berkuliah di Universitas Teknologi Sumbawa
}

\author{
Nora Dery Sofya ${ }^{1}$ dan Koko Hermanto*2 \\ ${ }^{1}$ Jurusan Teknik Informatika, Fakultas Rekayasa Sistem, Universitas Teknologi Sumbawa, Jl. Raya Olat Maras ds. \\ Batu Alang Kec. Moyo Hulu Kab. Sumbawa NTB, 84371, Indonesia \\ ${ }^{2}$ Jurusan Teknik Industri, Fakultas Rekayasa Sistem, Universitas Teknologi Sumbawa, Jl. Raya Olat Maras ds. Batu \\ Alang Kec. Moyo Hulu Kab. Sumbawa NTB, 84371, Indonesia \\ Email: nora.dery.sofya@uts.ac.id ${ }^{1}$, koko.hermanto@uts.ac.id ${ }^{2}$
}

\begin{abstract}
Abstrak
Banyaknya jumlah perguruan tinggi di tingkat nasional maupun lokal berakibat munculnya persaingan antar perguruan tinggi dalam mendapatkan calon mahasiswa. Oleh karena itu perguruan tinggi dituntut untuk menampilkan segala potensi dan keunggulannya masing-masing di setiap aspek, tidak terkecuali Universitas Teknologi Sumbawa (UTS) walaupun saat ini telah berada di peringkat lima besar dari seluruh perguruan tinggi di Nusa Tenggara Barat (NTB). Berdasarkan hal tersebut, tujuan dari penelitian ini adalah ingin menganalisis faktor-faktor yang terdiri dari kualitas pelayanan, kepuasan konsumen dan experiental marketing yang selama ini dilaksanakan oleh UTS telah memberikan pengaruh terhadap pemasaran teknik word of mouth secara optimal atau tidak dalam menarik minat calon mahasiswa untuk berkuliah di UTS. Hasil penelitian ini dapat memberikan gambaran bagi UTS dalam memberikan pelayanan kepada mahasiswa dalam pelayanan administrasi yang dilakukan oleh staf maupun dosen dalam memberikan pengajaran. Populasi dari penelitian ini adalah mahasiswa UTS yang masih bersetatus kuliah dengan sampel penellitian sebanyak 165 mahasiswa. Guna mencapai tujuan dari penelitian ini, data hasil kuesioner dari responden diuji menggunakan metode Structural Equation Modeling (SEM) dengan menggunakan software LISREL 8.8. Berdasarkan hasil penelitian diperoleh persamaan struktural: word of mouth $=-21 \times$ kualitas pelayanan $+0,3 \times$ kepuasan konsumen $+0,71 \times$ experiental marketing dengan $\mathrm{R}^{2}=71 \%$ dan hasil pengujian hipotesis menunjukkan dari ketiga variabel tersebut hanya variabel experiental marketing sebagai faktor yang berpengaruh positif dan signifikan terhadap keputusan word of mouth mahasiswa UTS.
\end{abstract}

Kata kunci: Word of mouth, kualitas pelayanan, kepuasan konsumen, experiental marketing, SEM.

\begin{abstract}
Many universities at the national and local levels have resulted in the emergence of competition between universities in obtaining prospective students. Therefore, universities have to show all their potential and advantages in every aspect, including the Universitas Teknologi Sumbawa (UTS), even though it is ranked in the top five universities in West Nusa Tenggara. This study aims to analyze the factors of service quality, customer satisfaction, and experiential marketing that UTS has implemented has influenced the marketing of word-of-mouth techniques optimally or not in attracting prospective students to study at UTS. This study's results can provide an overview for UTS in providing services to students with administrative services carried out by staff and lecturers in teaching. This study's population was UTS students who were still actively studying with a research sample of 165 students. In order to achieve the objectives of this study, questionnaire data from respondents were tested by using the Structural Equation Modeling (SEM) method using LISREL 8.8 software. The research results obtained a structural equation: word of mouth $=-21$ $\times$ service quality $+0.3 \times$ customer satisfaction $+0.71 \times$ experiential marketing with $R 2=71 \%$. The hypothesis testing results show that of the three variables, only experiential marketing variables have a positive and significant effect on UTS students' word of mouth decision.
\end{abstract}

Keywords: Word of mouth, service quality, customer satisfaction, experiential marketing, SEM.

\section{Pendahuluan}

Jumlah perguruan tinggi di Indonesia saat ini tidak kurang dari 2.800, dimana sebanyak 2.700 adalah Perguruan Tinggi Swasta (PTS) dan sebanyak 100 merupakan Perguruan Tinggi Negri (PTN). Oleh karena banyaknya jumlah perguruan tinggi menyebabkan persaingan antara perguruan tinggi di Indonesia baik PTS 
maupun PTN sangat ketat dalam merebutkan "pasar" dalam menarik minat mahasiswa (Muhardi, 2004).

Perguruan tinggi menjadi garda terdepan dalam menghasilkan sumber daya manusia yang bermutu. Keadaan persaingan saat ini yang cukup ketat antar perguruan tinggi menuntut lembaga pedidikan untuk memperhatikan mutu pendidikan pada suatu kelembagaan sehingga mampu dan lebih unggul dalam persaingan tersebut.

Dalam hal ini perguruan tinggi harus merencanakan langkah antisipasi guna menghadapi persaingan yang kompetitif serta bertanggung jawab dalam meningkatkan segala aspek pelayanan yang dimiliki oleh perguruan tinggi karena sebuah pelayanan yang dimiliki oleh lembaga tertentu akan menjadi Gambaran dari kualitas lembaga tersebut. Sebuah lembaga dapat dikatakan baik jika pelayanan yang diberikan menurut konsumen itu baik. Tapi sebaliknya jika layanan yang dimiliki suatu lembaga buruk maka lembaga tersebut juga dikatakan buruk pula termasuk juga layanan dalam sebuah lembaga pendidikan (Asmony, Handajani, Herwanti, \& Pituringsih, 2020).

Menghadapi persaingan dalam mendapatkan calon mahasiswa maka perguruan tinggi harus menampilkan berbagai potensi dan keunggulan yang dimiliki untuk dapat dikerahkan semaksimal mungkin. Salah satu yang harus dimiliki oleh perguruan tinggi agar tetap eksis dalam menghadapi persaingan denga perguruan tinggi lain adalah branding. Selain persaingan antar perguruan tingkat nasional, saat ini juga perguruan tinggi asing makin gencar melakukan promosi untuk menarik minat calon mahasiswa asal Indonesia. Beberapa strategi branding untuk meningkatkan minat calon mahasiswa adalah akreditasi, peningkatan kualitas jasa melalui sistem informasi, Chief marketing officer, promosi, beasiswa, different, mempunyai pusat career center, alumnus sebagai pemasar perguruan tinggi, publikasi universitas, dan sering mengikuti konferensi internasional (Sevima, 2017).

Joesyiana (2018) menyatakan bahwa pemasaran merupakan salah satu sarana bagi perusahaan untuk mencapai tujuan yang telah ditetapkan. Agar tujuan tersebut tercapai, maka setiap perusahaan harus berupaya menghasilkan dan menyampaikan barang atau jasa sesuai dengan keinginan konsumen dengan memberikan pelayanan pribadi menyenangkan dan fasilitas yang menunjang. Salah satu strategi promosi yang digunakan untuk menarik minat konsumen adalah word of mouth atau biasa disebut dengan promosi dari mulut ke mulut.

Word of mouth mempunyai peran yang sangat efektif dalam kelangsungan hidup suatu perusahaan. Karena promosi menggunakan teknik ini mampu menyebar luas dengan cepat dan dipercaya oleh calon konsumen. Pemasaran teknik ini dikataan efektif karena kegiatan promosi ini berdasarkan pengalaman pribadi seseorang dalam mengkonsumsi suatu produk atau jasa dari suatu perusahaan. Oleh karena itu puas dan tidak puasnya seoramg konsumen sangat berpengaruh pada dampak promosi word of mouth baik positif maupun negatif yang timbul sehingga dapat mempengaruhi perusahan tersebut. Seseorang konsumen dapat menjadi juru pembicara suatu produk lebih efektif dan meyakinkan dibandingkan iklan jenis apapun, maka perusahan harus memberikan pelayanan yang prima agar konsumennya terpuaskan (Tifani \& Widiyanto, 2015).

Masyarakat Indonesia lebih percaya terhadap informasi-informasi dari temannya dibandingkan dengan iklan maupun tenaga penjual. Konsumen akan lebih mudah percaya pada sumber yang dikenal daripada sales dari perusahaan tersebut (Hermawan Kertajaya, 2008). Konsumen yang tidak puas terhadap pelayanan yang diberikan oleh suatu lembaga cendrung akan mencerikan hal tersebut kepada sembilan atau sepuh orang. Sedangkan jika konsumen tersebut puas terhadap pelayanan perusahaan maka akan mencerikan pengalamannya kepada empat sampai lima orang saja (Gitomer, 1998).

Kualitas layanan merupakan suatu tindakan untuk memenuhi kebutuhan, keinginan konsumen dan ketepatan dalam mengimbangi keinginan konsumen. Kualitas pelayanan dapat diukur dengan lima indikator yaitu keandalan, jaminan, bukti fisik, empati dan daya tanggap (Panjaitan \& Yuliati, 2016).

Kepuasan konsumen adalah perbandingan antara persepsi konsumen terhadap hasil pengalaman yang dirasakan terhadap produk yang bersangkutan. Dapat berupa perasaan konsumen setelah membandingkan antara harapan konsumen dengan kinerja nyata oleh perusahaan. Apabila kinerja perusahaan jauh lebih rendah ketimbang harapan, konsumen merasa tidak puas, jika kinerja melebihi harapan, maka konsumen merasa amat puas. Konsumen yang merasa sangat puas dan yang merasa puas akan ringan dalam memberikan informasi kepada orang lain tentang pengalaman baik dengan kinerja yang telah dirasakan. Kuncinya adalah memenuhi harapan konsumen. Kepuasan konsumen dapat diukur dari kepuasan secara keseluruhan, kesan yang baik dan kejujuran (Kotler \& Lane, 2009).

Experiential Marketing adalah membangun hubungan yang langgeng antara perusahan dan konsumen melalui lima aspek yaitu panca indera, perasaan, cara berpikir, kebiasaan serta relasi. Dimana saat ini semua produk atau jasa harus bisa memenuhi kelima aspek tersebut (Kartajaya, 2002).

Saat ini Provinsi Nusa Tenggara Barat (NTB) memiliki 61 perguruan tinggi yang tediri dari 3 PTN dan 58 PTS. Banyaknya jumlah PT tersebut menyebabkan terjadinya persaingan tingkat lokal. Adapun lima besar terbaik PT tingkat NTB yang dirilis oleh Unirank pada tahun 2020 berturut-turut adalah Universitas Mataram, Universitas Hamzanwadi, Universitas Islam Negeri Mataram, Universitas Muhammadiyah Mataram dan Universitas Teknologi Sumbawa. Berdasarkan perangkingan tersebut menarik untuk ditelusuri strategi 
yang dilakukan oleh Universitas Teknologi Sumbawa yang merupakan perguruan tinggi swasta yang berkembang dengan sangat cepat, masih berumur tujuh tahun telah berada pada posisi lima besar terbaik di provinsi NTB.

Universitas Teknologi Sumbawa (UTS) salah satu perguruan tinggi swasta yang berada di kabupaten Sumbawa, saat ini memiliki enam fakultas yang terdiri dari Fakultas Teknik, Fakultas Teknobiologi, Fakultas Ekonomi dan Bisnis, Fakultas Teknologi Pertanian, Fakultas Ilmu Komunikasi dan Fakultas Psikologi. Berdasarkan data sistem akademik jumlah mahasiswa UTS saat ini adalah 3.886 orang yang berasal dari berbagai daerah di Indonesia dan ada juga mahasiswa asing yang berasal dari luar negri.

Berdasarkan pemaparan di atas maka tujuan dari penelitian ini adalah untuk mengetahui pengaruh kualitas pelayanan, kepuasan konsumen dan experiental marketing terhadap promosi Universitas Teknologi Sumbawa menggunakan teknik word of mouth. Guna mencapai hal tersebut maka dalam penelitian ini menggunakan pendekatan penelitian kuantitatif dengan menggunkan metode SEM dan bantuan software LISREL 8.8 .

Análisis dengan mekanisme ini telah diaplikasikan sebelumya antara lain oleh Yuliani (2012) tentang pengaruh kualitas pelayanan, kepuasan konsumen dan experiental marketing terhadap word of mouth pada Taman Pengembangan Anak Makara Fakultas Psikologi Universitas Indonesia, dengan menggunakan regresi berganda dengan bantuan análisis data menggunakan software SPSS. Muhammad Tahir Jan, Kalthom Abdullah:, \& Ali Shafiq, (2013) menganalisis pengaruh kepuasan pelangan Conventional Banks of Malaysia Investigated terhadap word of mouth dengan menggunakan metode SEM dan batuan software AMOS. Zulherwan \& Abror (2019) juga telah menganalisis pengaruh satisfaction, trust, commitment terhadap word of mouth pada rumah makan Sambalado di kota Padang dengan menggunakan metode SEM. Selain untuk menganalisa word of mouth, metode SEM dapat juga digunakan untuk menganalisa faktor-faktor yang mempengaruhi kepuasan (Hermanto, Suarantalla, Utami, \& Sudirman, 2020) serta dapat diaplikan dalam menganalisa faktor-faktor eksistensi suatu ritel (Suarantalla \& Hermanto, 2020).

\section{Metode Penelitian}

Guna mendapatkan pemahaman pemahaman dari suatu persoalan maka penelitian ini menggunakan studi kasus. Langkah pertama yang yang dilakukan adalah menentukan populasi dan sampel penelitian, Populasi penelitian adalah mahasiswa Universitas Teknologi Sumbawa (UTS) yang masih bersetatus aktif kuliah. Berdasarkan informasi yang diperoleh dari Sistem Akademik (SIAKAD) UTS diperoleh total jumlah mahasiswa yang aktif sebanyak 3.886 orang sehingga dengan menggunakan metode Solvin, dengan error $10 \%$ diperoleh minimal jumlah sampel yang diperlukan dalam penelitian ini adalah 97 mahasiswa.

Langkah selanjutnya adalah melakukan penyebaran kuesioner. Data yang digunakan dalam penelitian ini adalah data primer, diperoleh dengan membagikan kuesioner melalui google form ke mahasiswa UTS. Jumlah mahasiswa aktif yang telah bersedia mengisi kuisioner sebanyak 165 mahasiswa hal ini memenuhi syarat sampel yang telah ditetapkan sebelumnya yaitu lebih besar dari 97 mahasiswa. Indikator pertanyaan pada kuesioner merupakan perkembangan dari kuesioner penelitian yang dilakukan oleh Yuliani (2012) Kuisioner yang digunakan terdiri dari empat kategori yaitu kualitas pelayanan $\left(X_{1}\right)$, kepuasan konsumen $\left(X_{2}\right)$ experiental marketing $\left(X_{3}\right)$ dan word of mouth $(Y)$.

Berdasarkan penelitian yang pernah dilakukan oleh Yang \& He (2011) dan Yuliani (2012) Kerangka berfikir dalam penelitian ini adalah kualitas pelayanan $\left(X_{1}\right)$, kepuasan konsumen $\left(X_{2}\right)$ dan experiental marketing $\left(X_{3}\right)$ merupakan variabel-variabel bebas atau variabel eksogen mempengaruhi word of mouth $(Y)$ yang merupakan variabel terikat atau variabel endogen.

Setelah data kuesioner terkumpul maka langkah selanjutnya yang dilakukan adalah melakukan uji validitas dan uji reliabilitas dengan menggunakan software Listrel 8.8. Data dikatakan valid jika nilai standardized loading factor $(\lambda)$ lebih besar dari 0,5 atau idealnya lebih besar dari 0,7 . Nilai construct reliability (CR) yang masih dapat diterima adalah 0,5 dan idealnya 0,7 . Sedangkan untuk nilai rata-rata variance extracted (AVE) lebih besar dari 0,7 sangat bagus sedangkan di atas 0,5 masih dapat diterima. Menentukan nilai CR dan AVE berturut-turut dapat ditentukan dengan menggunakan persamaan (1) dan persamaan (2) (Bollen and J. Scotth Long, 1993; G. David Garson, 2011).

$$
C R=\frac{\left(\sum_{i=1}^{n} \lambda_{y i}\right)^{2}}{\left(\sum_{i=1}^{n} \lambda_{y i}\right)^{2}+\left(\sum_{i=1}^{n} \operatorname{var}\left(\varepsilon_{i}\right)\right)}
$$

dimana

$C R$ : indek reliabilitas komposit;

$\lambda_{y}$ : Standardized loading faktor;

$\operatorname{var}\left(\varepsilon_{i}\right)$ : varians error pengukuran.

$$
A V E=\frac{\sum_{i=1}^{n} \lambda_{i}^{2}}{n}
$$

Dimana

$A V E$ : rata-rata ekstrak varians

$\lambda_{i}$ : standardized loading faktor ke- $i$

$n$ : jumlah ítem.

Setelah model dinyatakan valid dan reliabel maka langkah selanjutnya adalah melakukan uji kelayakan model dari model SEM yang telah dibentuk dari persoalan dengan menggunakan software Listrel 8.8. Edi Riadi (2016) menyatakan bahwauntuk mengetahui fit 
atau tidak suatu model SEM dapat diukur menggunakan goodness of fit dengan ketentuan seperti pada Tabel 1.

Tabel 1. Goodness of Fit Index

\begin{tabular}{llll}
\hline No. & Goodness of Fit Index & Cut off value & Keriteria \\
\hline \multirow{2}{*}{1.} & Chi-Square $\left(\chi^{2}\right)$ & $0 \leq \chi^{2} \leq 2 \mathrm{df}$ & $\begin{array}{l}\text { Good fit } \\
\text { Marginal fit }\end{array}$ \\
\cline { 2 - 3 } & Probability & $>0,05$ & \\
\hline 2. & Root Mean Error of & $\leq 0,01-0,05$ & Good fit \\
& Approximation & $0,08-0,10$ & Marginal fit \\
& (RMSEA) & & \\
\hline 3. & Normed Fit Index (NFI) & $\geq 0,90$ & Good fit \\
& & $0,80-0,98$ & Marginal fit \\
\hline 4. & Tucker Lewis Index & $\geq 0,90$ & Good fit \\
& (NNFI) & $0,80-0,98$ & Marginal fit \\
\hline 5. & Comrave Fit Index & $\geq 0,90$ & Good fit \\
& (CFI) & $0,80-0,98$ & Marginal fit \\
\hline 6. & Incrumental Fit Index & $\geq 0,90$ & Good fit \\
& (IFI) & $0,80-0,98$ & Marginal fit \\
\hline 7. & Goodness of Fit Index & $\geq 0,90$ & Good fit \\
& (GFI) & $0,80-0,98$ & Marginal fit \\
\hline 8. & Ajusted Goodness of Fit & $\geq 0,90$ & Good fit \\
& Index (AGFI) & $0,80-0,98$ & Marginal fit \\
\hline
\end{tabular}

Langkah selanjutnya adalah menyususn hubungan antara varibel endogen dan variabel eksogen. Hubungan tersebut dapat dianalisis melalui model persamaan struktural yang akan dibentuk dari penelitian ini yaitu berdasarkan persamaan (3):

$$
Y=a_{1} X_{1}+a_{2} X_{2}+a_{3} X_{3}
$$

dimana

$Y$ : variabel endogen atau variabel terikat

$X_{i}$ : variabel eksogen atau variabel bebas, $i=1,2,3$.

$a_{j}$ : konstanta, $j=1,2,3$

Langkah terakhir adalah menentukan variabelvariabel eksogen yang berpengaruh signifikan terhadap variabel eksogen melalui pengujian hipotesis. Adapun hipotesis yang digunakan dalam penelitian ini adalah sebagai berikut.

$\mathrm{H}_{01}$ : Terdapat pengaruh yang tidak signifikan faktor layanan terhadap word of mouth mahasiswa UTS.

$\mathrm{H}_{\mathrm{a} 1}$ : Terdapat pengaruh yang signifikan faktor layanan terhadap word of mouth mahasiswa UTS.

$\mathrm{H}_{02}$ : Terdapat pengaruh yang tidak signifikan faktor kepuasan konsumen terhadap word of mouth mahasiswa UTS.

$\mathrm{H}_{\mathrm{a} 2}$ : Terdapat pengaruh yang signifikan faktor kepuasan konsumen terhadap word of mouth mahasiswa UTS.

$\mathrm{H}_{03}$ : Terdapat pengaruh yang tidak signifikan faktor experiental marketing terhadap word of mouth mahasiswa UTS.

$\mathrm{H}_{\mathrm{a} 3}$ : Terdapat pengaruh yang signifikan faktor experiental marketing terhadap word of mouth mahasiswa UTS.

\section{Hasil dan Pembahasan}

\subsection{Deskripsi Karaktrestik Responden}

Objek dalam penelitian ini adalah mahasiswa Universitas Teknologi Sumbawa (UTS) yang masih berstatus aktif kuliah. Jumlah mahasiswa yang ikut mengisi form kuisioner sebanyak 165 mahasiswa.

\subsection{Confirmatory Faktor Analysis (CFA)}

Pada teknik análisis penelitian menggunakan SEM, terlebih dahulu akan menyeleksi beberapa variabel yang diangap sebagai indikator yang layak dari sebuah faktor. CFA bertujuan untuk menganalisis dimensionalitas suatu konstruk atau variabel. Umumnya sebelum melakukan análisis model struktural terlebih dahulu harus melakukan pengukuran model untuk menguji validitas dan realibilitas dari indikator-indikator pembentuk konstruk tersebut dengan melakukan CFA (Latan, 2012).

Output model pertama CFA dengan menggunakan dengan menggunakan Lisrel 8.8 dapat dilihat pada Gambar 1.

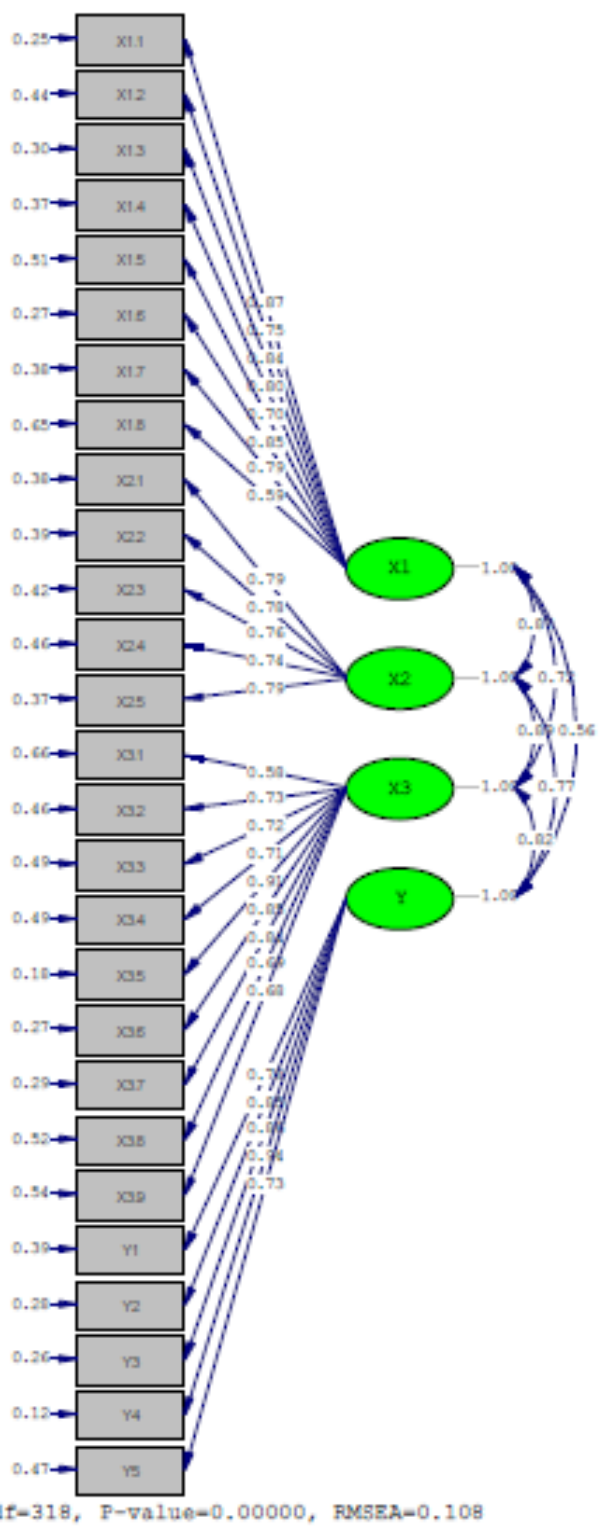

Gambar 1. Model CFA pertama 
Pada Gambar 1 menunjukan diagram jalur dalam model CFA pertama masih terdapat nilai muatan faktor loading yang kurang dari 0,7 yaitu pada variabel layanan $\left(X_{1}\right)$ yaitu $X_{1.8}$, variabel experiental marketing $\left(X_{3}\right)$ yaitu $X_{3.1}, X_{3.6}$ dan $X_{3.7}$. berdasarkan hal tersebut, maka model CFA pertama belum dikatakan valid maka indikatorindikator yang tidak memenuhi tersebut dibuang dari model, dan dilakukan anlisa model CFA ulang tanpa menggunakan indikator-indikator yang nilai muatan faktor loading kurang dari 0,7. Pada output model CFA kedua masih memiliki nilai muatan faktor loading kurang dari 0,7 yaitu hanya pada variabel layanan $\left(X_{1}\right)$ yaitu indikator $X_{1,5}$. Maka dilakukan analisa model CFA lagi tanpa menggunakan indikator yang kurang dari 0,7. Proses analisa model CFA terus diulang hingga proses berhenti pada Output model keenam.

Pada output model CFA keenam disajikan pada Gambar 2 tidak ditemukan lagi muatan loading faktor variabel dan indikator yang kurang dari 0,7 maka dapat disimpulkan indikator-indikator pada variabel kualitas pelayanan, kepuasan konsumen, experiental marketing dan Word of mouth sudah valid. Adapun indikatorindikator yang dibuang dan tidak dikutkan dalam analisa selanjutnya yaitu:

1. Pada variabel layanan $\left(X_{1}\right)$ indikator-indikator yang dibuang adalah $X_{1,2}$ dan $X_{1,5}$.

2. Pada variabel kepuasan konsumen experiental marketing $\left(X_{3}\right)$ indikator-indikator yang dibuang adalah $X_{3,1}, X_{3,3}, X_{3,4}, X_{3,8}$ dan $X_{3,9}$.

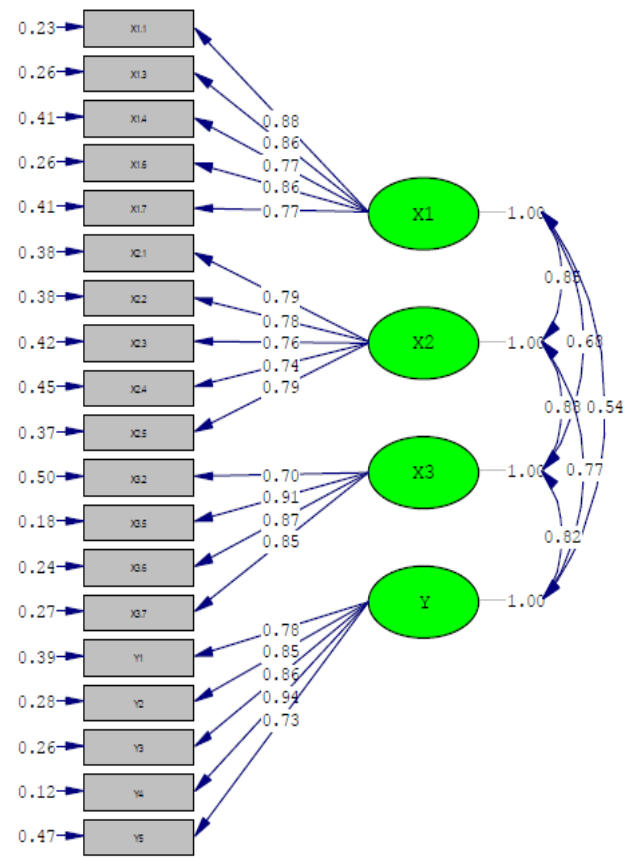

Chi-Square=432.20. df $=146$. P-value=0.00000. RMSEA=0.109 Gambar 2. Model CFA kedua

Berdasarkan model CFA pada Gambar 3 dan persamaan (2) dapat dianalisis perhitungan reliabilitas disajikan pada Tabel 2.
Tabel 2. Uji Validitas dan Reliabilitas Variabel Komunikasi dan variabel Pelayanan

\begin{tabular}{|c|c|c|c|c|c|}
\hline Variabel & Indikator & $\lambda$ & Error & CR & AVE \\
\hline \multirow{5}{*}{$\begin{array}{l}\text { Kualitas } \\
\text { pelayanan } \\
\left(X_{1}\right)\end{array}$} & $X_{1.1}$ & 0,84 & 0,29 & \multirow{5}{*}{0,9} & \multirow{5}{*}{0,7} \\
\hline & $X_{1.3}$ & 0,84 & 0,29 & & \\
\hline & $X_{1.4}$ & 0,77 & 0,40 & & \\
\hline & $X_{1.6}$ & 0,89 & 0,21 & & \\
\hline & $X_{1.7}$ & 0,76 & 0,42 & & \\
\hline \multirow{5}{*}{$\begin{array}{l}\text { Kepuasan } \\
\text { konsumen } \\
\left(X_{2}\right)\end{array}$} & $X_{2.1}$ & 0,74 & 0,45 & \multirow{5}{*}{0,9} & \multirow{5}{*}{0,6} \\
\hline & $X_{2.2}$ & 0,79 & 0,37 & & \\
\hline & $X_{2.3}$ & 0,76 & 0,42 & & \\
\hline & $X_{2.4}$ & 0,76 & 0,42 & & \\
\hline & $X_{2.5}$ & 0,80 & 0,37 & & \\
\hline \multirow{4}{*}{$\begin{array}{l}\text { Experiental } \\
\text { marketing } \\
\left(X_{3}\right)\end{array}$} & $X_{3.2}$ & 0,71 & 0,50 & \multirow{4}{*}{0,9} & \multirow{4}{*}{0,6} \\
\hline & $X_{3,5}$ & 0,87 & 0,24 & & \\
\hline & $X_{3,6}$ & 0,83 & 0,31 & & \\
\hline & $X_{3,7}$ & 0,88 & 0,23 & & \\
\hline \multirow{5}{*}{$\begin{array}{l}\text { Word of } \\
\text { mouth }(Y)\end{array}$} & $Y_{1}$ & 0,71 & 0,49 & \multirow{5}{*}{0,9} & \multirow{5}{*}{0,7} \\
\hline & $Y_{2}$ & 0,80 & 0,37 & & \\
\hline & $Y_{3}$ & 0,86 & 0,26 & & \\
\hline & $Y_{4}$ & 0,98 & 0,07 & & \\
\hline & $Y_{5}$ & 0,74 & 0,45 & & \\
\hline
\end{tabular}

Berdasarkan Tabel 2 dapat dilihat bahwa nilai Construct Reliability (CR) dan rata-rata ekstrak varian (AVE) dari setiap konstruk variabel di atas 0,5. Oleh karena itu, dapat disimpulkan bahwa semua variabel dnan indikator penelitian dalam full model mempunyai reliabilitas dan validitas yang baik.

\subsection{Analisis Structural Equation Modeling (SEM)}

Hasil analisis full model SEM berdasarkan standar loading yang telah diperoleh pada Gambar 2 ditampilkan pada Gambar 3.

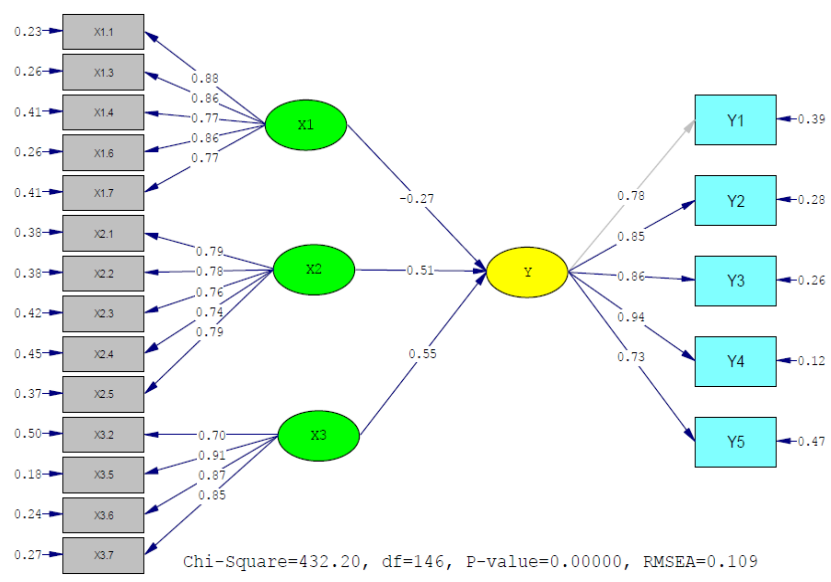

Gambar 3. Basic Model Standardized Solution

Berdasarkan output Goodnes of Fit Statistic dari software Lisrel diperoleh hasil uji Goodnes of Fit model word of mouth belum fit karena banyak Goodness of Fit Index yang ditetapkan pada Tabel 1 belum memenuhi kriteria, seperti nilai RMSEA $=0,109$, nilai $\mathrm{GFI}=0,78$ dan nilai $\mathrm{AGFI}=0,72$. Oleh karena itu dilakukan pembebasan error variance antar variabel manifes bertujuan untuk mengurangi nilai statistik Chi-square yang terlalu besar 
(Haryono, 2016). Sehingga diperoleh output basic model standadized solustion setelah dimodifikasi disajikan pada Gambar 4.

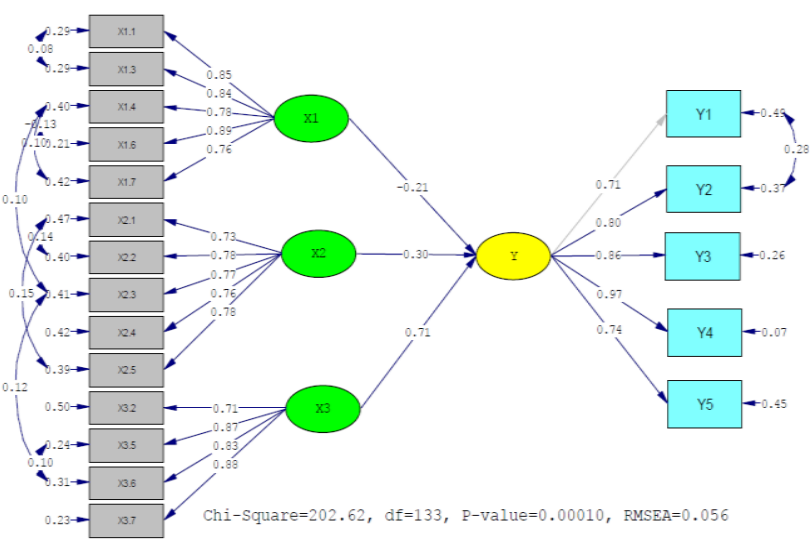

Gambar 4. Basic Model Standardized Solution Modifikasi

Output Goodnes of Fit Statistic dari software Lisrel setelah model dimodifikasi disajikan pada Tabel 3.

Tabel 3. Goodnes of Fit model word of mouth

\begin{tabular}{|c|c|c|c|c|}
\hline No. & $\begin{array}{l}\text { Goodness of Fit } \\
\text { Index }\end{array}$ & Value & Cut off value & Keriteria \\
\hline \multirow[t]{2}{*}{1.} & Chi-Square $\left(\chi^{2}\right)$ & 202,62 & $\begin{array}{l}0 \leq \\
\chi^{2} \leq 2 \times 162\end{array}$ & Good fit \\
\hline & Probability & 0,00010 & $\begin{array}{l}>0,05 \\
0,01-0,05\end{array}$ & \\
\hline 2. & $\begin{array}{l}\text { Root Mean Error } \\
\text { of Approximation } \\
\text { (RMSEA) }\end{array}$ & 0,56 & $\begin{array}{l}\leq 0,08 \\
0,08-0,10\end{array}$ & Good fit \\
\hline 3. & $\begin{array}{l}\text { Normed Fit Index } \\
\text { (NFI) }\end{array}$ & 0,98 & $\begin{array}{l}\geq 0,90 \\
0,80-0,98\end{array}$ & Good fit \\
\hline 4. & $\begin{array}{l}\text { Tucker Lewis } \\
\text { Index (NNFI) }\end{array}$ & 0,99 & $\begin{array}{l}\geq 0,90 \\
0,80-0,98\end{array}$ & Good fit \\
\hline 5. & $\begin{array}{ll}\text { Comrave } & \text { Fit } \\
\text { Index }(\mathrm{CFI}) & \end{array}$ & 0,99 & $\begin{array}{l}\geq 0,90 \\
0,80-0,98\end{array}$ & Good fit \\
\hline 6. & $\begin{array}{ll}\text { Incrumental } & \text { Fit } \\
\text { Index (IFI) } & \end{array}$ & 0,99 & $\begin{array}{l}\geq 0,90 \\
0,80-0,98\end{array}$ & Good fit \\
\hline 7. & $\begin{array}{l}\text { Goodness of Fit } \\
\text { Index (GFI) }\end{array}$ & 0,88 & $\begin{array}{l}\geq 0,90 \\
0,80-0,98\end{array}$ & Good fit \\
\hline 8. & $\begin{array}{l}\text { Ajusted } \\
\text { Goodness of Fit } \\
\text { Index (AGFI) }\end{array}$ & 0,84 & $\begin{array}{l}\geq 0,90 \\
0,80-0,98\end{array}$ & $\begin{array}{l}\text { Marginal } \\
\text { fit }\end{array}$ \\
\hline
\end{tabular}

Berdasarkan hasil uji Goodnes of Fit pada Tabel 4 dapat disimpulkan bahwa model variabel word of mouth dinyatakan fit atau layak maka dapat digunakan pada structural equation model untuk mengetahui apakah faktor-faktor kualitas pelayanan $\left(X_{1}\right)$, kepuasan konsumen $\left(X_{2}\right)$ experiental marketing $\left(X_{3}\right)$ mempengaruhi word of mouth $(Y)$. Berdasarkan hasil stándar loading yang terdapat pada Gambar 5 dan persamaan (3), diperoleh persamaan struktural pada persamaan (4).

$$
Y=-0,21 X_{1}+0,3 X_{2}+0,71 X_{3}
$$

dimana

$Y$ : word of mouth

$X_{1}$ : kualitas pelayanan

$X_{2}:$ kepuasan konsumen

\section{$X_{3}$ : experiental marketing}

Sedangkan tingkat kepercayaan $\left(R^{2}\right)$ yang diperoleh dari persamaan (3) adalah sebesar $71 \%$. Artinya keputusan word of mouth yang dilakukan oleh mahasiswa UTS dipengaruhi oleh kualitas pelayanan, kepuasan konsumen, dan experiental marketing sebesar $71 \%$, sisanya dipengaruhi oleh variabel lain yang tidak digunakan pada penelitian ini.

Hasil analisis full model SEM berdasarkan t-value disajikan pada Gambar 5.

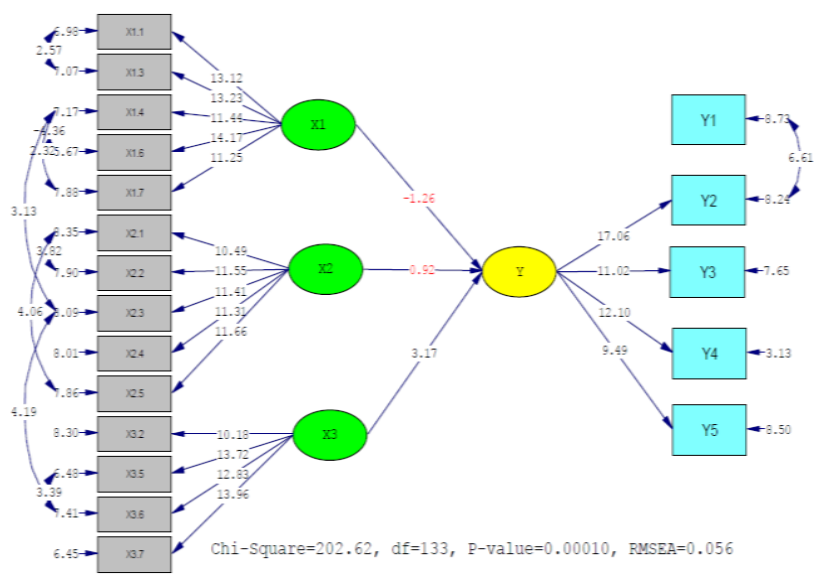

Gambar 5. Full Model based on t-value

Berdasarkan Gambar 5 tersebut, dapat diperoleh informasi bahwa variabel experiental marketing $\left(X_{3}\right)$ terhadap word of mouth $(Y)$ pada full model signifikan. Sedangkan kualitas pelayanan $\left(X_{1}\right)$ terhadap word of mouth $(Y)$ dan kepuasan konsumen $\left(X_{2}\right)$ terhadap word of mouth $(Y)$ tidak signifikan nilai ( $t$-value kurang dari 1,96) pada tingkat keyakinan $95 \%$. Secara umum hasil uji hipótesis dan estimasi penelitian disajikan pada Tabel 4.

Tabel 4. Uji Hipotesis

\begin{tabular}{clccc}
\hline Hipotesis & Path & $\begin{array}{l}\mathrm{t}- \\
\text { value }\end{array}$ & $\begin{array}{l}\text { Esti- } \\
\text { masi }\end{array}$ & Hasil \\
\hline $\mathrm{H}_{\mathrm{a} 1}$ & $\begin{array}{l}\text { Pelayanan } \rightarrow \text { Word of } \\
\text { mouth }\end{array}$ & $-1,26$ & $-0,21$ & Ditolak \\
\hline $\mathrm{H}_{\mathrm{a} 2}$ & $\begin{array}{l}\text { kepuasan konsumen } \\
\rightarrow \text { Word of mouth }\end{array}$ & 0,92 & 0,30 & Ditolak \\
\hline $\mathrm{H}_{\mathrm{a} 3}$ & $\begin{array}{l}\text { experiental marketing } \\
\rightarrow \text { Word of mouth }\end{array}$ & 3,17 & 0,71 & Diterima \\
\hline
\end{tabular}

Berdasarkan Tabel 4, dapat dilihat bahwa hipotesis pertama $\left(\mathrm{H}_{\mathrm{a} 1}\right)$ terbukti ditolak karena t-value sebesar 1,26 (pada tingkat keyakinan 95\%) < 1,96 yang berarti terdapat hubungan yang tidak signifikan anatara variabel Pelayanan terdadap word of mouth mahasiswa UTS. Sedangkan nilai estimasinya sebesar $-0,21$ berarti pengaruh variabel Pelayanan berpengaruh negatif dan tidak signifikan terhadap word of mouth mahasiswa UTS.

Pelayanan terhadap word of mouth mahasiswa didapatkan hasil hubungan yang negatif, oleh karena itu dapat diartikan apabila pihak UTS semakin sering memberikan pelayanan maka mahasiswa semakin banyak mengetahui hal-hal yang kurang dari pelayanan 
UTS yang dapat menurunkan word of mouth mahasiswa. Oleh karena itu pihak UTS harus meningkatkan kualitas pelayanan, yaitu ketanggapan, keandalan, empati, jaminan dan tangible.

Hipotesis kedua $\left(\mathrm{H}_{\mathrm{a} 2}\right)$ dapat dilihat pada Tabel 4 terbukti ditolak ditolak karena t-value sebesar 0,92 (pada tingkat keyakinan 95\%) < 1,96 yang berarti terdapat hubungan yang tidak signifikan anatara variabel kepuasan konsumen terdadap word of mouth mahasiswa UTS. Sedangkan nilai estimasinya sebesar 0,30 berarti pengaruh variabel Pelayanan berpengaruh positif dan tidak signifikan terhadap word of mouth mahasiswa UTS.

Hubungan kepuasan kosumen terhadap word of mouth mahasiswa didapatkan hasil hubungan yang positif, oleh karena itu dapat diartikan mahasiswa yang semakin merasa puas dengan pelayanan pihak UTS maka mahasiswa akan tertarik melakukan word of mouth tentang UTS. Karena hubungannya tidak signifikan maka harus meningkatkan indikator kepuasan konsumen berupa kepuasan secara keseluruhan, kesan yang baik dan kejujuran.

Hipotesis kedua $\left(\mathrm{H}_{\mathrm{a} 3}\right)$ dapat dilihat pada Tabel 4 terbukti diterima karena t-value sebesar 3,17 (pada tingkat keyakinan 95\%) > 1,96 yang berarti terdapat hubungan yang signifikan antara variabel experiental marketing terdadap word of mouth mahasiswa UTS. Sedangkan nilai estimasinya sebesar 0,30 berarti pengaruh variabel experiental marketing berpengaruh positif dan signifikan terhadap word of mouth mahasiswa UTS.

Hubungan eksperiental marketing terhadap word of mouth mahasiswa didapatkan hasil hubungan yang positif, oleh karena itu dapat diartikan apabila experiental marketing mahasiswa semakin baik maka mahasiswa akan tertarik melakukan word of mouth tentang UTS. Oleh karena itu pihak UTS tetap mempertahankan dan meningkatkan pelaksanaan indikator eksperiental marketing yang selama ini telah dilakukan berupa kegiatan yang berhubungan dengan panca indera, perasa, pikiran, tindakan dan hubungan.

\section{Kesimpulan}

Berdasarkan hasil penelitian yang telah diperoleh maka dapat ditarik kesimpulan sebagai berikut, dari ketiga variabel yang digunakan yaitu kualitas pelayanan, kepuasan konsumen dan experiental marketing hanya variabel experiental marketing sebagai faktor yang berpengaruh positif dan signifikan terhadap Word of mouth mahasiswa UTS. Oleh karena itu perlu adanya peningkatan untuk meningkatkan nilai ukur indikator pada kedua variabel tersebut.

\section{Ucapan Terima Kasih}

Tim peneliti mengucapkan terimakasih kepada rektor Universitas Teknologi Sumbawa serta jajarannya yang telah memberikan dana hibah pada penelitian ini.

\section{Daftar Pustaka}

Asmony, T., Handajani, L., Herwanti, T., \& Pituringsih, E. (2020). Pelatihan Sistem Informasi Berbasis Komputer Bagi Pegawai Kontrak Fakultas Ekonomi Dan Bisnis Universitas Mataram Guna Meningkatkan Kualitas Pekerjaan. Jurnal PEPADU, 1(1), 15-23. Retrieved from http://jurnal.lppm.unram.ac.id/index.php/jurnalpe padu/article/view/69

Bollen, K. A., \& J. Scotth Long. (1993). Testing structural equation models. Sage Focus Editions, 154.

Edi Riadi. (2016). Statistik SEM - Structural Equation Modeling dengan Lisrel (1st ed.; E. Kurnia, Ed.). Jakarta: Andi.

G. David Garson. (2011). Structural Equation Modeling. Retrieved from http://faculty.chass.ncsu.edu/garson/PA765/struct ur.htm

Gitomer, J. (1998). Customer Satisfaction Is Worthless, Customer Loyalty Is Priceless: How to Make Customers Love You, Keep Them Coming Back and Tell Everyone They Know. Austin: TX Bard Press.

Haryono, S. (2016). SSEM method for management research with AMOS 22.00, LISREL 8.80 and Smart PLS 3.0 (1st ed.; H. Mintardja, Ed.). Yogyakarta: PT. Intermedia Personalia Utama.

Hermanto, K., Suarantalla, R., Utami, S. F., \& Sudirman. (2020). Application of SEM in analyzing student satisfaction with administrative services. Journal of Physics: Conference Series, 1663(1), 1-8. https://doi.org/10.1088/1742-6596/1663/1/012008

Hermawan Kertajaya. (2008). Seri 9 Elemen Marketing Hermawan Kartajaya on Marketing Mix. Bandung: Mizan Pustaka. Retrieved from http://www.bukabuku.com/browses/product/9789 794334355/seri-9-elemen-marketing-hermawankartajaya-on-service.html

Joesyiana, K. (2018). Pengaruh Word Of Mouth Terhadap Keputusan Pembelian Konsumen Pada Media Online Shop Shopee Di Pekabaru (Survey pada Mahasiswa Semester VII Jurusan Pendidikan Akuntansi Fakultas Keguruan dan Ilmu Pendidikan Universitas Islam Riau). Valuta, 4(1), 71-85.

Kartajaya, H. (2002). On Marketing. Jakarta: Gramedia Pustaka Utama.

Kotler, P., \& Lane, K. (2009). Manajemen pemasaran (1st ed.). Jakarta: Erlangga. Retrieved from http://lib.ui.ac.id/detail.jsp?id=20363249\#parentH orizontalTab5

Muhammad Tahir Jan, Kalthom Abdullah:, \& Ali Shafiq. (2013). The Impact of Customer Satisfaction on Word-of-Mouth. International Journal of Information Technology \& Computer Science, 10(3), 10 .

Muhardi. (2004). Aspek-Aspek Keunggulan Bersaing Perguruan Tinggi. Mibar, 20(2), 179-193. https://doi.org/https://doi.org/10.29313/mimbar.v2 $0 \mathrm{i} 2.135$

Panjaitan, J. E., \& Yuliati, A. L. (2016). Pengaruh Kualitas Pelayanan Terhadap Kepuasan Pelanggan 
Pada JNE Cabang Bandung [The Influence of Service Quality on Customer Satisfaction at JNE Branch in Bandung]. DeReMa (Development Research of Management): Jurnal Manajemen, 11(2), 265. https://doi.org/10.19166/derema.v11i2.197

Sevima, A. (2017). Strategi Branding Perguruan Tinggi Untuk Menarik Minat Mahasiswa Baru. Retrieved April 1, 2021, from Sevima.com website: https://sevima.com/strategi-branding-perguruantinggi-untuk-menarik-minat-mahasiswa-baru/

Suarantalla, R., \& Hermanto, K. (2020). Analisis Faktor yang Mempengaruhi Eksistensi Ritel Tradisional di Kecamatan Sumbawa Menggunakan Structural Equation Modeling. Performa, 19(2), 185-198. https://doi.org/10.20961/performa.19.2.44682

Tifani, A. G., \& Widiyanto, I. (2015). Minat Word of Mouth Pada Produk Perumahan Graha Padma Semarang. Diponegoro Journal of Management, 4(3), 1-11.

Yang, Z., \& He, L. (2011). Goal, customer experience and purchase intention in a retail context in China: An empirical study. African Journal of Business Management, 5(16), 6738-6746. https://doi.org/10.5897/AJBM10.1287

Yuliani, P. S. (2012). Analisis Pengaruh Kualitas Pelayanan, Kepuasan Konsumen, Dan Experiential Marketing Terhadap Word of Mouth. Universitas Indonesia.

Zulherwan, \& Abror. (2019). Pengaruh Satisfaction, Trust , Commitment Terhadap Word of Mouth Pada Rumah Makan Sambalado di Kota Padang. Jurnal Kajian Manajemen Dan Wirausaha, 01(September 2018), 331-343. 